\title{
Herpes simplex virus type 1 infection and glucocorticoid treatment regulate viral yield, glucocorticoid receptor and NF-кB levels
}

\author{
A C Erlandsson, L-G Bladh, P Stierna ${ }^{1}$, T Yucel-Lindberg ${ }^{2}$, \\ O Hammarsten ${ }^{3}$, T Modéer ${ }^{2}$, J Harmenberg ${ }^{4}$ and A-C Wikström \\ Department of Medical Nutrition, Karolinska Institutet, Novum, S-141 86 Huddinge, Sweden \\ ${ }^{1}$ ENT, Department of Clinical Science, Huddinge University Hospital, 14186 Huddinge, Sweden \\ ${ }^{2}$ Institute of Odontology, Department of Pediatric Dentistry, Karolinska Institutet, 14186 Huddinge, Sweden \\ ${ }^{3}$ Department of Clinical Chemistry, Gothenburg University, Sahlgren's University Hospital, 41345 Gothenburg, Sweden \\ ${ }^{4}$ Medivir AB, Lunastigen 7, 14144 Huddinge, Sweden \\ (Requests for offprints should be addressed to A-C Wikström; Email: lotta.wikstrom@mednut.ki.se)
}

\begin{abstract}
The interplay between the endocrine and immune systems has come into focus in recent years with the insight that endocrine parameters may affect susceptibility to both auto-immune and infectious diseases. Our interest in immunoendocrine regulation led us to investigate the effects of glucocorticoids on Herpes simplex virus type 1 (HSV-1) infections. Glucocorticoids used to treat inflammatory conditions are not yet recommended for HSV-1 therapy, since they have been reported to prolong viral shedding both in vivo and in vitro. Here we report that glucocorticoids did not alter the viral yield in human gingival fibroblast (HGF) cell culture when glucocorticoid treatment and viral infection occured simultaneously, but the viral yield increased when cells were treated with the glucocorticoid dexamethasone (dex) prior to viral infection. We found that viral infection in our primary cell
\end{abstract}

system increased $\mathrm{NF}-\kappa \mathrm{B}$ levels and DNA binding. In addition, the amount of glucocorticoid receptor (GR) increased following viral infection, and HSV-1 infection as such could induce glucocorticoid-driven transcription of a reporter gene in human embryo kidney (HEK) 293 cells stably transfected with GR. Dex treatment did not affect HSV-1-induced binding of p65 to an NF- $\kappa$ B element in an electrophoretic mobility shift assay, and acyclovir was still efficient as an anti-viral drug in the presence of dex. Further studies of the observed effects of HSV-1 infection and glucocorticoid treatment on $\mathrm{GR}$ and $\mathrm{NF}-\kappa \mathrm{B}$ regulation could give insights into the immunoendocrine mechanisms important for defence and therapy against viral infections.

Journal of Endocrinology (2002) 175, 165-176

\section{Introduction}

Herpes simplex virus type 1 (HSV-1) causes fever blisters or genital lesions that are the result of both a viral cytopathic effect and a massive inflammatory response. Currently HSV-1 lesions are treated with anti-viral drugs that, if taken orally and in the early phase of the infection, have an inhibitory effect on viral replication but do not counteract the painful inflammation. It has therefore been of interest to treat the lesions with anti-inflammatory substances, for example glucocorticoids. However, this approach is controversial since it has been suggested that glucocorticoid treatment may increase the viral yield in vitro (Harrell \& Sydiskis 1982, Dreyer et al. 1989), while other reports suggest a decreased viral yield (Notter \& Docherty 1978). In PC12 cells differential glucocorticoid effects have been shown to be dependent on both viral replication origin and cellular differentiation (Hardwicke
\& Schaffer 1997). This may be related to a putative glucocorticoid response element (GRE) in the oriL, one of the two different origins of replication within the HSV-1 genome (Hardwicke \& Schaffer 1995). Glucocorticoids have also been shown to have an effect on human immunodeficiency virus type-1 (HIV-1) replication, however, as for HSV-1, the nature of the effects are disputed. Some reports showed a slight increase in HIV-1 replication (Markham et al. 1985, 1986) while others reported an inhibitory effect (Kino et al. 2000). The half-perfect GRE within the HIV-1 long terminal repeat (LTR) promoter (Ghosh 1992) which can bind dimerised and ligandactivated glucocorticoid receptor (GR), may play a role in glucocorticoid effects on HIV-1 replication. Kino and co-workers (2000) suggested that the inhibitory effect of glucocorticoids on the HIV-1 LTR may be exerted via non-GRE-dependent inhibition of the strongly positive host transcription factor NF- $\mathrm{KB}$ or by competition with/ 
squelching of other transcription factors. In Kino et al.'s experiments glucocorticoids suppressed, rather than stimulated, the HIV-1 promoter. In cases where an increased viral replication is obtained it may be due to glucocorticoid-mediated immunosuppression of the host.

Glucocorticoids mediate their effects by binding to the intracellular GR (reviewed in Adcock 2000 and Newton 2000). In the absence of ligand GR is sequestered in the cytoplasm, bound to several other proteins in a multiprotein complex. The receptor is a ligand-activated transcription factor that upon activation is released from the multiprotein complex and translocates to the nucleus where it binds as a homodimer to specific recognition sequences, called GREs. The GR is important in the regulation of several target genes involved in a broad spectrum of vital physiological processes. Glucocorticoids can act as potent anti-inflammatory agents as they repress the expression of cytokines, adhesion molecules and enzymes involved in the inflammatory process (Barnes \& Adcock 1993). The anti-inflammatory effects of glucocorticoids are largely considered to be exerted via crosstalk with pro-inflammatory signalling pathways via protein-protein interactions. Of special interest is the interaction with $\mathrm{NF}-\mathrm{\kappa B}$, which is a pro-inflammatory transcription factor important in the early cellular response to pathogens and which acts to promote inflammation (Barnes \& Karin 1997). NF-KB and GR mutually antagonise the effects of one another and hereby glucocorticoids can act in an anti-inflammatory way (Caldenhoven et al. 1995). In a normal cell NF- $\mathrm{KB}$ is retained in the cytoplasm by an inhibitory protein, IкB. In response to a variety of stimuli including viral and bacterial pathogens, cytokines and stress activators, the cytoplasmic NF- $\mathrm{KB}$ pathway is activated. The I $\mathrm{KB}$ protein is then phosphorylated and thereby destined for subsequent degradation (Baldwin 1996). The released and activated NF- $\mathrm{KB}$ dimer translocates to the nucleus and regulates transcription of target genes by binding to specific NF- $\mathrm{KB}$ sites in DNA.

Like many viruses, HSV-1 influences cellular host mechanisms in order to promote its own propagation. HSV-1 has been shown to induce the pro-inflammatory mediator NF-KB (Rong et al. 1992, Patel et al. 1998, Amici et al. 2001). The persistent nuclear translocation of $\mathrm{NF}-\kappa \mathrm{B}$ in HSV-1 infected cells has been further shown to coincide with increased binding of NF- $\mathrm{KB}$ to specific DNA response elements (Patel et al. 1998). Whether the increased DNA-bound NF- $\mathrm{KB}$ reflects increased activity and subsequent transcription of target genes is not clear, as Patel et al. (1998) report decreased expression of a reporter gene, while others report increased transcription (Rong et al. 1992, Amici et al. 2001). Although increased GR expression or activity has not been reported in response to HSV-1 infection, other pathogens have been shown to mediate increased GR activity. Tomita and co-workers (1985) reported that human lymphocytes transformed with Epstein-Barr virus showed both increased concentration and number of glucocorticoid binding sites as compared with non-transformed cells. Further, HIV is thought to mediate increased GR activity via the viral protein Vpr, which acts as a coactivator for GR, and thereby upregulates transcription of GR-dependent genes (Refaeli et al. 1995, Kino et al. 1999).

To further study the effects of glucocorticoids on HSV-1 infection we used primary gingival fibroblasts, an untransformed cell line that can be considered to be a natural target for HSV-1 infection. Dexamethasone (dex) treatment prior to infection (pre-treatment) increased viral yield, whereas dex co-treatment had no impact on viral yield. As we found that glucocorticoid treatment had differential effects on the viral yield depending on the timing of the glucocorticoid treatment we were interested to investigate how HSV-1 infection, with or without glucocorticoid treatment, affected two proteins central in the control of inflammatory and anti-inflammatory events, GR and NF- $\kappa B$. We found, as previously reported for HSV-1 infection in a variety of cell lines, that the nuclear expression of NF- $\mathrm{KB}$ in our primary cell culture was upregulated in response to $\mathrm{HSV}-1$ infection and that binding of an NF- $\mathrm{KB}$ element in an electromobility shift assay (EMSA) was induced. In addition to the increased nuclear NF- $\mathrm{KB}$ expression, we also observed a nuclear translocation and an increase in GR protein levels that has not previously been reported in HSV-1 infected cultures. We also found that HSV-1 infection could lead to an increased glucocorticoid-driven reporter gene activity in GR-deficient human embryo kidney cell line 293 (HEK 293) stably transfected with GR. Furthermore, dex treatment prior to infection led to lower levels of GR being detected from the time of infection up to $24 \mathrm{~h}$ postinfection (p.i.), as compared with the high GR levels in infected, untreated or infected, co-treated cells. We suggest that up-regulation of GR may be one factor of importance in the defence against HSV-1 infection.

\section{Material and Methods}

\section{Cells and virus}

Human primary gingival fibroblasts (HGF) were obtained from gingival biopsies from healthy volunteers, a procedure approved by the ethical committee at Huddinge University Hospital. The fibroblasts were propagated in high glucose Dulbecco's modified Eagle medium (DMEM, GibcoBRL Laboratories Inc., Gaithersburg, MD, USA), supplemented with $8 \%$ foetal bovine serum (FBS) (Sigma Chemical Co., St Louis, MO, USA), $100 \mu \mathrm{g} / \mathrm{ml}$ streptomycin and $100 \mathrm{U} / \mathrm{ml}$ penicillin (GibcoBRL Laboratories Inc.) at $37^{\circ} \mathrm{C}$ in $5 \% \mathrm{CO}_{2}$.

African green monkey kidney cells (Vero cells; a gift from the Swedish Institute for Infectious Disease Control, Solna, Sweden) were propagated in Earl's modified Eagle medium (GibcoBRL Laboratories Inc.) supplemented as 
described above with the exception of the addition of $2 \mathrm{mM}$ L-glutamine (GibcoBRL Laboratories) at $37^{\circ} \mathrm{C}$ in $5 \% \mathrm{CO}^{2}$.

The C42 p2 strain of HSV-1 (a clinical isolate obtained from the Swedish Institute for Infectious Disease Control, Solna, Sweden) was grown and titrated in Vero cells. The cell media containing the virus was collected and cell debris was removed by subsequent centrifugation of the virus supernatant at $1800 \mathrm{~g}$ for $6 \mathrm{~min}$.

Clones of either the GR-deficient HEK 293 (293wt), or HEK 293 cells stably transfected with the wild-type GR construct (293-GR) were grown in a 1:1 mixture of high glucose, DMEM and Ham's F-12 (GibcoBRL Laboratories Inc.), supplemented with 10\% FBS (Sigma Chemical Co.), $2 \mathrm{mM}$ L-glutamine (GibcoBRL Laboratories), $100 \mu \mathrm{g} / \mathrm{ml}$ Hygromycin B (GibcoBRL Laboratories Inc.) and $100 \mu \mathrm{g} / \mathrm{ml}$ Zeocin (Invitrogen Corporation, Carlsbad, CA, USA) at $37{ }^{\circ} \mathrm{C}$ in $5 \% \mathrm{CO}_{2}$.

\section{Virus infection}

HGF cells were seeded in $75 \mathrm{~cm}^{2}$ flasks at a density of $2 \times 10^{6}$ cells/flask $72 \mathrm{~h}$ prior to dex pre-treatment. At $70 \%$ confluence a share of the flasks were pre-treated with $1 \mu \mathrm{M}$ dex (Sigma Chemical Co.). After $24 \mathrm{~h}$ incubation the confluent cells were washed twice in PBS and inoculated with the C42 p2 strain, of HSV-1 diluted in serum-free medium, at a multiplicity of infection (MOI) of $10^{-3}$ plaque-forming units (pfu)/cell for further analysis of viral yield, or MOI of $3 \mathrm{pfu} /$ cell for protein isolation. After $1 \mathrm{~h}$ of adsorption at $37^{\circ} \mathrm{C}$ in $5 \% \mathrm{CO}_{2}$, serumsupplemented medium containing either $1 \mu \mathrm{M}$ acyclovir (ACV, Sigma Chemical Co.), $1 \mu \mathrm{M}$ dex or a combination of the two was added to cells either pre-treated or not pre-treated with dex. Cells were incubated for an additional $24 \mathrm{~h}$ and supernatants were then removed and frozen at $-80{ }^{\circ} \mathrm{C}$ for further analyses in the plaque assays. The cells were harvested for protein isolation (see below).

\section{Plaque assay}

Vero cells were plated in 24-well multidishes at a density of $2 \times 10^{5}$ cells/well $72 \mathrm{~h}$ before infection. At confluence, the cells were inoculated with the viral HGF supernatants (see above), diluted in serum-free medium, and subsequently incubated for $1 \mathrm{~h}$ for virus adsorption. The cells were washed in PBS and fresh medium supplemented with $10 \% \mathrm{FBS}$ and $2 \mathrm{mg} / \mathrm{ml}$ human immunoglobulin was added (Beriglobin, Centeon Pharma GmBh, Marburg, Germany). The infection proceeded for 3 days, after which cells were stained with $70 \%$ crystal violet (Sigma) in ethanol and plaques were counted. Results are shown as $\mathrm{pfu} / \mathrm{ml}$.

\section{Cytosol and nuclear extract preparation}

HGF cell cultures were harvested by scraping and subsequently pelleted by centrifugation. The cell pellets obtained were resuspended in buffer $(10 \mathrm{mM}$ Hepes $\mathrm{pH}$ $7.9, \quad 1.5 \mathrm{mM} \mathrm{MgCl}, 10 \mathrm{mM} \mathrm{KCl}, 0.5 \mathrm{mM}$ DTT, $0 \cdot 2 \mathrm{mM}$ PMSF) and left on ice for $15 \mathrm{~min}$. The suspensions were subsequently centrifuged for $30 \mathrm{~s}$ at $13000 \boldsymbol{g}$ at $4{ }^{\circ} \mathrm{C}$. The cytosol fractions were decanted and the remaining pellets were dissolved in a high salt buffer (20 mM Hepes pH 7.9, 25\% glycerol, $420 \mathrm{nM} \mathrm{NaCl}$, $1.5 \mathrm{mM} \mathrm{MgCl}_{2}, 0.2 \mathrm{mM}$ EDTA, $0.5 \mathrm{mM}$ DTT, $0.2 \mathrm{mM}$ PMSF) and left on ice for $20 \mathrm{~min}$. The suspensions were subsequently centrifuged for $5 \mathrm{~min}$ at $13000 \times \boldsymbol{g}$ at $4{ }^{\circ} \mathrm{C}$.

\section{$N F-\kappa B$ and GR expression: SDS-PAGE and Western blot}

Protein concentrations were determined in a Bradford assay (BioRad). Equal amounts of total protein were run on SDS-PAGE ( $9 \%$ polyacrylamide gel) under reducing conditions and blotted to polyvinylidene difluoride membrane (BioRad). The membranes were subsequently protein-stained with ponceau solution (Sigma) for confirmation of successful, and equal, protein transfer and equal protein amounts. The membranes were further destained in PBS. After blocking with 5\% defatted dry milk, the membranes were incubated with primary antibodies directed against either GR (sc-1003, Santa Cruz Biotechnology Inc., Santa Cruz, CA, USA) or p65 (sc-109, Santa Cruz Biotechnology Inc.), diluted in PBS and 1\% defatted dry milk for $1.5 \mathrm{~h}$ at room temperature. After washing in PBS with $0.5 \%$ Tween 20, the polyvinylidene difluoride membranes were incubated with horseradish peroxidaseconjugated secondary antibody (Amersham Pharmacia Biotech), diluted in PBS and 1\% defatted dry milk for $1 \mathrm{~h}$ at room temperature. The membranes were again washed in PBS and incubated with Supersignal WestFemtoMaximumSensitivitySubstrate (Pierce, Rockford, IL, USA) for $5 \mathrm{~min}$. The chemiluminescence signals were detected and semi-quantified in a Fuji LAS-1000 image analyser.

\section{GR transactivation activity: transient transfection and GRE-luciferase reporter assay}

$1 \times 10^{6}$ cells of each HEK cell clone (293wt and 293-GR) were seeded into two separate $25 \mathrm{~cm}^{2}$ cell culture flasks and incubated overnight at $37^{\circ} \mathrm{C}$ in $5 \% \mathrm{CO}_{2}$. The cells were transfected with $1 \mu \mathrm{g}$ of the previously described (GRE) ${ }_{2}$ tk-luciferase (luc) (Schule et al. 1988) reporter plasmid diluted in serum-free medium using lipofectine according to the manufacturer's recommendations (GibcoBRL Laboratories Inc.). After $6 \mathrm{~h}$ of incubation, culture medium was added and the cells were incubated overnight at $37^{\circ} \mathrm{C}$ in $5 \% \mathrm{CO}_{2}$. The semi-adherent cells were collected in serum-free media in two separate tubes, each cell suspension was divided into two separate tubes and centrifuged at $1600 \boldsymbol{g}$ for $5 \mathrm{~min}$. The cell pellets were resuspended in serum-free media, the cell suspensions recentrifuged at $1600 \mathrm{~g}$ for $5 \mathrm{~min}$ and the supernatants withdrawn. Each cell pellet was diluted in either $1 \mathrm{ml}$ of 
serum-free medium (mock) or $1 \mathrm{ml}\left(3 \times 10^{6} \mathrm{pfu} / \mathrm{ml}\right)$ virus suspension (HSV-1) and triplicates of $300 \mu \mathrm{l}$ each were seeded in a $24-w e l l$ plate and incubated at $37^{\circ} \mathrm{C}$ in $5 \%$ $\mathrm{CO}_{2}$. After $1 \mathrm{~h}$ of viral adsorption, $1 \mathrm{ml}$ of cell culture media was added and the cells were further incubated at $37^{\circ} \mathrm{C}$ in $5 \% \mathrm{CO}_{2}$. At 24 h p.i. the media was withdrawn and $40 \mu \mathrm{l}$ of lysis buffer $(25 \mathrm{mM}$ TAE $\mathrm{pH} 7 \cdot 8,1 \mathrm{mM}$ EDTA, 10\% glycerol, $1 \%$ Triton-X100 and 2 mM DTT ) were added to each well. The cells were lysed by freeze-thawing, $30 \mu \mathrm{l}$ from each lysate were mixed with the Luc-ScreenJ kit from PE Biosystems (Tropix Inc., Bedford, MA, USA) according to the manufacturer's instructions, and luciferase activity was measured.

\section{NF- $\kappa B$ DNA-binding: EMSA}

Nuclear extracts were prepared as described above. Nuclear extract containing 4-8 $\mu$ g total protein was added to a $20 \mu \mathrm{l}$ binding reaction containing $20 \mathrm{mM}$ HEPES $\mathrm{pH}$ 7·8, $5 \mathrm{mM} \mathrm{MgCl} 2,100 \mathrm{mM} \mathrm{KCl}, 20 \%$ glycerol, $0 \cdot 1 \%$ Triton X-100 and $0 \cdot 1-0 \cdot 3$ ng ${ }^{32} \mathrm{P}-$ labelled oligonucleotide corresponding to the NF- $\mathrm{\kappa B}$ binding site from the human intercellular adhesion molecule-1 (ICAM-1) gene promoter (upper strand 5' GGA TTC TGG AAA TTC CCT TT $3^{\prime}$ ). A control experiment was performed inducing NF- $\kappa \mathrm{B}$ binding activity by treating HGF cells with tumour necrosis factor (TNF)- $\alpha(200 \mathrm{U} / \mathrm{ml})$ (Roche Diagnostics Scandinavia AB, Bromma, Sweden) for $1 \mathrm{~h}$ before preparing nuclear extract as described above. Supershifts were conducted by including $2 \mu \mathrm{l}$ of the p50 antibody sc-114 or the p65 antibody sc-109X (Santa Cruz Biotechnology Inc.) in the binding reaction. Specific and non-specific competition experiments were performed by including a 100-fold excess of non-labelled consensus oligonucleotide or the consensus oligonucleotide mutated at one base. The reactions were incubated for $20 \mathrm{~min}$ at room temperature and subsequently run on PAGE (4\% polyacrylamide, $0.25 \times$ TBE $(90 \mathrm{mM}$ Tris-borate, $2 \mathrm{mM}$ EDTA), 0.01\% NP-40). After electrophoresis the gels were dried and autoradiographed.

\section{Results}

Pre-treatment with dex up-regulated herpes simplex viral yield in human gingival fibroblasts

There are conflicting reports in the literature regarding the effects of glucocorticoids on HSV-1 replication and viral yield. We investigated the effect of the synthetic glucocorticoid, dex, on HSV-1 infection in confluent HGF cells.

We used a low MOI $\left(10^{-3} \mathrm{pfu} / \mathrm{cell}\right)$, to mimic the in vivo situation of the natural HSV-1 infection. The viral yield was measured at $24 \mathrm{~h}$ p.i. in a Vero cell viral plaque assay. The time point was chosen to correspond to the

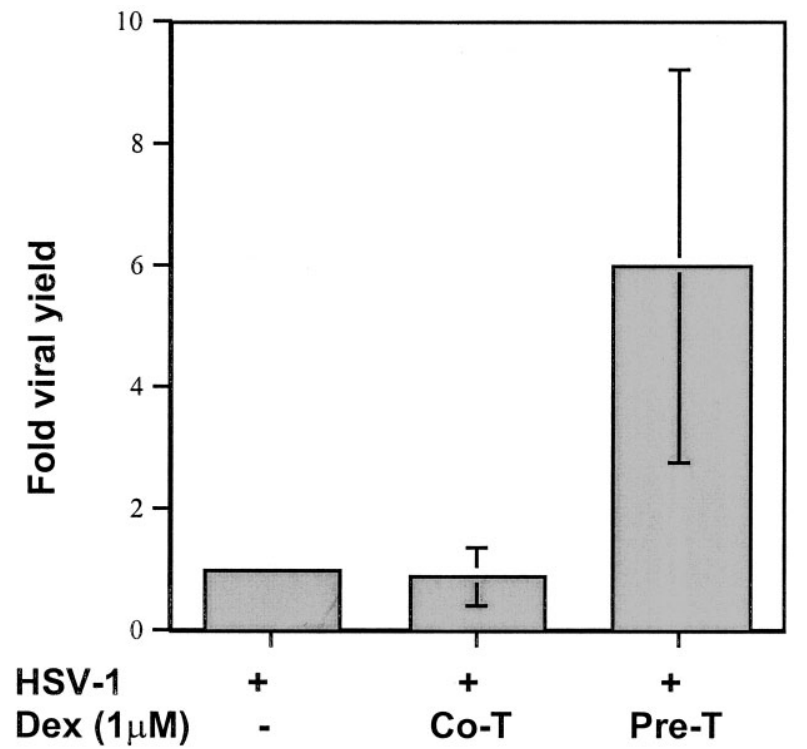

Figure 1 Viral yield in dexamethasone (dex) treated human gingival fibroblasts (HGFs). HGFs were untreated (-), co-treated (Co-T) with dex concurrent with, or pre-treated (Pre-T) with dex prior to, infection with herpes simplex virus type 1 (HSV-1, 10 ${ }^{-3}$ plaque-forming units (pfu)/cell) for $1 \mathrm{~h}$ at $37^{\circ} \mathrm{C}$. At $24 \mathrm{~h}$ post infection (p.i.) viral supernatants were removed and diluted to be assayed for pfu content by plaque assay.

viral production after one cycle of viral replication in a primary cell. When adding dex at the time of infection we did not observe any effect on viral yield compared with control cells where dex was not added. However, an increased virus production occurred when we pre-treated proliferating cells with dex $24 \mathrm{~h}$ prior to HSV-1 infection (Fig. 1). This result was obtained in several independent experiments. We concluded that dex treatment either had no effect on viral yield or increased viral yield as a consequence of the point at which it was added.

GR as well as NF- $\kappa B$ is up-regulated in response to HSV-1 infection of HGFs

HSV-1 infection has been shown to cause persistent nuclear translocation of NF- $\mathrm{\kappa B}$ (Patel et al.) and this is considered to be essential for efficient viral replication. As GR and NF- $\kappa B$ serve as mutual antagonists in inflammatory reactions (Barnes \& Adcock 1993, Caldenhoven et al. 1995) we were interested to study first if NF- $\kappa B$ translocation also occurred in HSV-1 infected HGF cells and furthermore, to see whether GR was also affected. Figure 2 shows a representative result from several such experiments. Western blotting was performed on cytosolic and nuclear extracts, probing the same extract for p65 - a subunit of the NF- $\mathrm{kB}$ dimer - and for GR. By using the same protein amount in all cytosolic and nuclear extracts we could perform semi-quantitative estimations of p65 and 


\section{Cytosol}

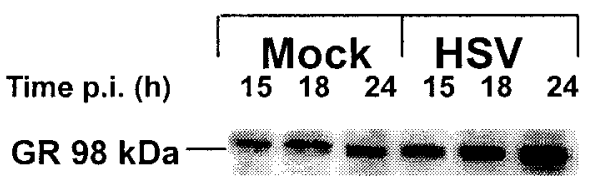

p65 65 kDa
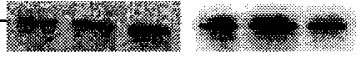

$\begin{array}{llllll}1 & 2 & 3 & 4 & 5 & 6\end{array}$

\section{Nucleus}

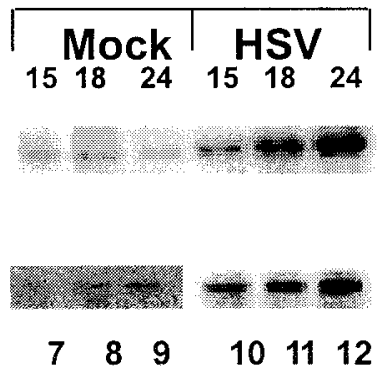

Figure 2 HSV-1 infection induces nuclear translocation of NF-kB and up-regulation of glucocorticoid receptor (GR) expression. HGF cells were infected with HSV-1 (3 pfu/cell) for $1 \mathrm{~h}$ at $37^{\circ} \mathrm{C}$. At different times (15, 18 and $\left.24 \mathrm{~h}\right)$ p.i. cytosolic and nuclear extracts from HSV-1 (HSV) or mock infected (Mock) cultures were prepared and assayed for the NF-kB subunit, p65, and GR expression by Western blotting. The immunostaining shown is semi-quantitative as the total protein applied to each lane is equal.

GR levels within the same experiment (Materials and Methods). The p65 and GR levels in cytosol and nucleus after 6,9 and $12 \mathrm{~h}$ p.i. (data not shown) were similar to the levels at $15 \mathrm{~h}$. HSV-1 infection resulted in a slight up-regulation of p65 as well as an increase in the nuclear localisation of p 65 , most notably at $24 \mathrm{~h}$ p.i., as compared with the amount in mock infected HGF cells (Fig. 2, compare lanes 10-12 with lanes 7-9 in the lower panel). We also noted an increase in GR protein levels in the cytosol (Fig. 2, compare lanes 4-6 with lanes 1-3 in the upper panel), as well as a GR nuclear translocation with increased levels of GR in the nucleus, also most obvious at 24 h p.i. (Fig. 2, compare lanes 10-12 with lanes 7-9 in the upper panel).

$H S V-1$ infection transactivates a (GRE) ${ }_{2}$-tk-luc reporter gene in HEK 293 cells stably transfected with GR

The increase of GR nuclear expression in HSV-1 infected cell cultures led us to investigate whether GR was activated in response to HSV-1 infection. To determine this, we investigated whether HSV-1 infection led to transactivation of a glucocorticoid-driven reporter gene. In preliminary experiments, where we transfected HGF cells with a GRE-containing reporter gene using lipofectine, we did not obtain consistent results in terms of transfection efficiency. Instead we used the GR-deficient HEK cell line 293 either as wildtype (293wt) or stably transfected with a full length GR construct (293-GR). The original GR-deficient 293wt as well as the 293-GR cells were transiently transfected with a reporter plasmid containing $(G R E)_{2}$-tk-luc. The cells were left to recover overnight and subsequently infected with HSV-1 (3 pfu/cell). At $24 \mathrm{~h}$ p.i. the cells were lysed and luciferase activity was measured (see Materials and Methods). HSV-1 infection caused an eightfold induction of the (GRE) $)_{2}$-tk-luc reporter gene in 293-GR cells as compared with mock infected cells (Fig. 3). In the original 293wt cells some induction of luciferase activity was noted, albeit at a lower level, probably reflecting a low endogenous amount of GR

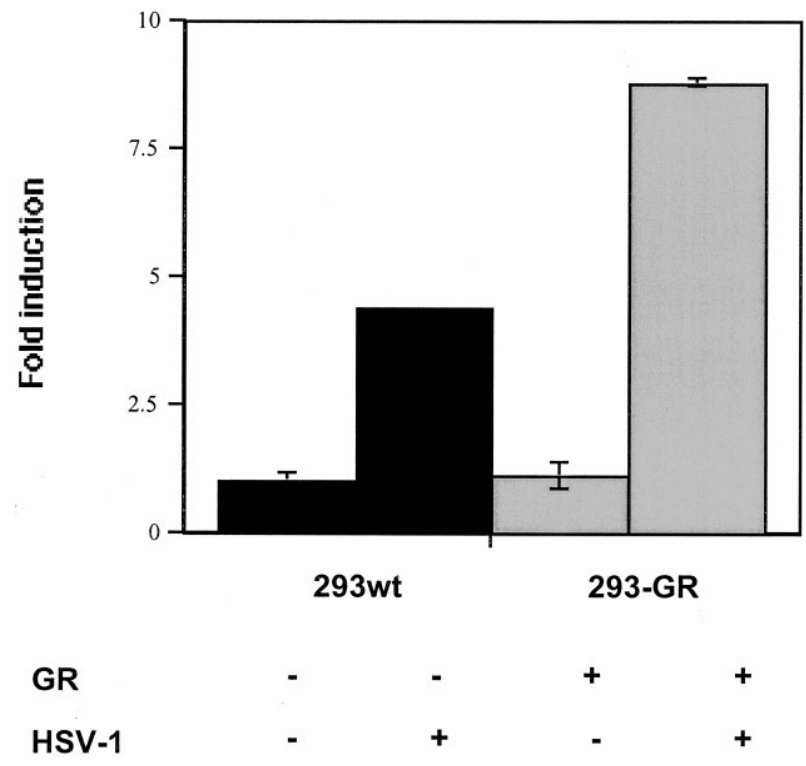

Figure 3 Increased nuclear GR transactivates a glucocorticoid response element (GRE) ${ }_{2}$-tk-luc reporter gene in a GR specific manner in HEK 293 cells. $1 \times 10^{6}$ cells of either GR deficient (293wt) or GR wild type-expressing (293-GR) HEK 293 cells were transfected with $1 \mu \mathrm{g}(\mathrm{GRE})_{2}$-tk-luc reporter plasmid. The cells were left to recover overnight at $37^{\circ} \mathrm{C}$ and subsequently $0.5 \times 10^{6}$ cells of each clone were infected with HSV-1 (3 pfu/cell) for $1 \mathrm{~h}$ at $37^{\circ} \mathrm{C}$. Triplicates of each clone were seeded in a 24-well plate and incubated at $37^{\circ} \mathrm{C}$. At $24 \mathrm{~h}$ p.i. the media were withdrawn and the cells were lysed. The cell lysates were mixed with the Luc-ScreenJ kit and luciferase bioluminescence was analysed. The results are obtained from triplicates and are presented as means ( \pm S.D.) fold induction compared with mock infected cells. 


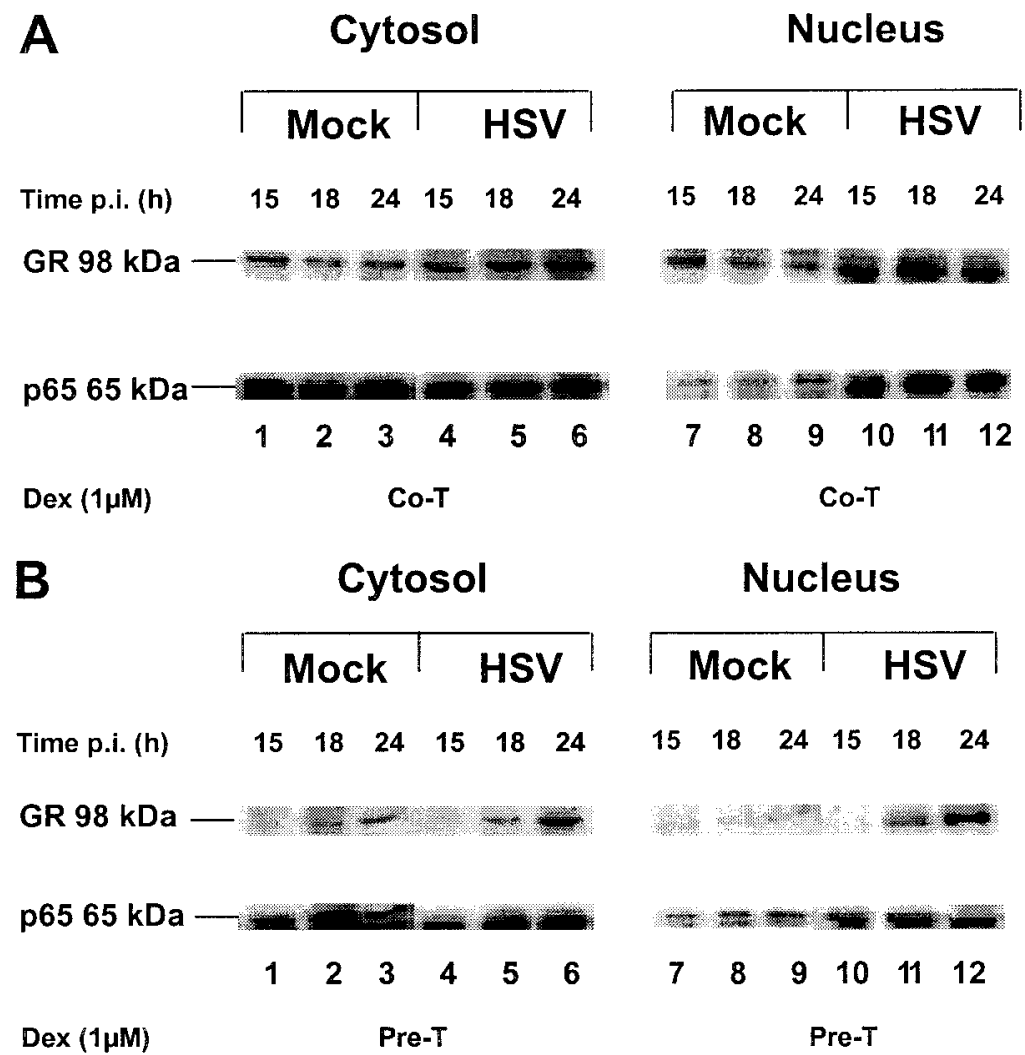

Figure 4 Effect of dex on NF-KB and GR expression in HSV-1 infected cell cultures. HGF cells were either (A) dex co-treated $(\mathrm{Co}-\mathrm{T})$ at the time of infection, or (B) pre-treated (Pre-T) $24 \mathrm{~h}$ prior to infection with HSV-1 (3 pfu/cell) for $1 \mathrm{~h}$ at $37^{\circ} \mathrm{C}$. At different times (15, 18 and $24 \mathrm{~h})$ p.i. cytosolic and nuclear extracts from HSV-1 (HSV) or mock infected (Mock) cultures were prepared and assayed for NF- $\mathrm{KB}$ and GR expression by Western blotting. The immunostaining shown is semi-quantitative as the total protein applied to each lane is equal.

in these cells. In summary HSV-1 infection led to upregulated GR activity in terms of transactivation.

Effects of dex on NF- $\kappa B$ and GR expression in primary HGFs infected with $H S V-1$

As we found that HSV-1 infection caused increased GR expression and could transactivate a GRE-dependent reporter gene, and that dex treatment caused a differential effect on HSV-1 viral yield depending on when dex was added, we were interested to see if there was a subsequent difference in GR and NF- $\mathrm{KB}$ localisation and levels in the two cases. Persistent nuclear translocation of NF- $\kappa B$ has been suggested to be necessary for efficient HSV-1 replication. We investigated whether the expression levels and the localisation of NF- $\mathrm{KB}$ were altered by dex administration either at the time of infection (co-treatment) or $24 \mathrm{~h}$ prior to HSV-1 infection (pre-treatment). The nuclear p65 expression in HSV-1 infected, dex-co-treated cells (Fig. 4A, lanes 10-12), as well as in pre-treated cells
(Fig. 4B, lanes 10-12) was similar to that observed in non-treated HSV-1-infected cells (Fig. 2, lanes 10-12). The addition of dex to HSV-1 infected cells did not affect the ability of NF- $\kappa \mathrm{B}$ to translocate, regardless of the time of dex administration. As neither expression nor nuclear translocation of $\mathrm{NF}-\mathrm{\kappa B}$ was altered, we were interested to study the effects of dex on the NF- $\kappa B$ opposing GR protein in this system. Dex treatment of mock infected cultures down-regulated the GR expression in accordance with previous studies (Dong et al. 1988, Erdeljan et al. 2001, Holloway et al. 2001). This down-regulation was time-dependent as dex-co-treated cells, when assayed at 15-24 h p.i., expressed higher levels of GR in both cytosol and nucleus compared with dex pre-treated cultures which had been exposed to dex for a period of $24 \mathrm{~h}$ prior to the measurements (compare Fig. 4A lanes 1-3 with Fig. 4B lanes 1-3 and Fig. 4A lanes 7-9 with Fig. 4B lanes 7-9 respectively). However, the dex treatment resulted in a slight decrease in GR expression in the co-treated cells and a marked decrease in the pre-treated cells, when 
compared with untreated cells (compare Fig. 4A and B lanes 1-3 and 7-9 with Fig. 2 lanes 1-3 and 7-9). HSV-1 infection led to an increased level of GR in dex treated cells. However, the increase differed between the pretreated and the co-treated cells. In co-treated cells infected with HSV-1, the up-regulation of both cytosolic and nuclear GR expression was similar to that observed in non-treated HSV-1-infected cells (compare Fig. 4A lanes 4-6 and 10-12 with Fig. 2 lanes 4-6 and 10-12), whereas the pre-treated cells did not upregulate GR to a similar extent (compare Fig. 4A lanes 4-6 and 10-12 with Fig. 4B lanes 4-6 and 10-12). From this experiment we could conclude that dex treatment of HGF cells prior to HSV-1 infection, which we previously found led to an increased viral yield (Fig.1), mainly affected the level and intracellular localisation of GR but not of p65. HSV-1 infection caused an up-regulation and nuclear translocation of p65 in HGF cells regardless of dex pre- or co-treatment. In contrast, the overall GR level was reduced and the nuclear translocation was both decreased and delayed in HSV-1-infected, dex-pre-treated, cells.

\section{The DNA binding of NF- $\kappa B$ is increased in $H S V-1$ infected cells}

To further clarify the importance of interplay between $\mathrm{NF}-\kappa \mathrm{B}$ and GR in relation to viral replication in a primary cell culture we first determined whether the increase of nuclear p65 was associated with an increased binding of p65 to its cognate DNA binding-site. An EMSA analysis of nuclear extracts from HSV-1-infected HGF cells showed increased binding to an NF- $\mathrm{\kappa B}$ site corresponding to the one present in the ICAM-1 promoter (Fig. 5A, lanes 4-6). The EMSA analysis resulted in two distinctly retarded complexes in HSV-1 infected cells at 15-24 h p.i. in contrast to the non-infected cells. The late time points were chosen to correspond to the time at which we had observed the increased nuclear expression of p65. Furthermore, we noted a change in the abundance of the two bands over time. At $15 \mathrm{~h}$ p.i. the faster migrating complex was dominant (Fig. 5A, lane 4), whereas at $24 \mathrm{~h}$ p.i. the slower migrating complex predominated (Fig. 5A, lane 6). The composition of these two complexes with different mobilities was further analysed. Both were specific in the sense that they could be competed for by addition of 100 times excess of the unlabelled ICAM-1 oligonucleotide (Fig. 5A, lane 8), and were unaffected by the addition of 100 times excess of a point-mutated ICAM-1 oligonucleotide (Fig. 5A, lane 9). Furthermore, both complexes contained the two NF- $\kappa$ B subunits, p50 and p65, as they were both supershifted by anti-p50 (Fig. 5A, lane 10) and anti-p65 antibodies (Fig. 5A, lane 11). As proteolysis sometimes gives rise to multiple bands in EMSA experiments, we performed a control experiment using an established NF- $\kappa B$ inducing agent, TNF- $\alpha$, for comparison. This experiment demonstrated that the faster
A

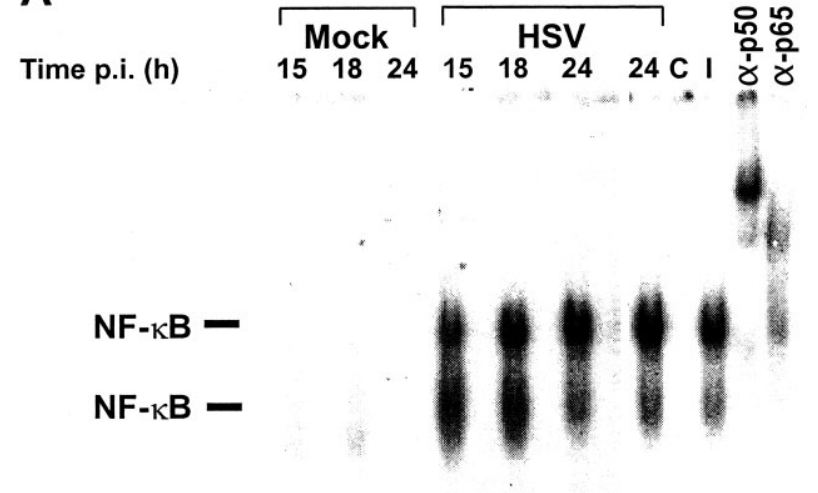

$\begin{array}{lllllllllll}1 & 2 & 3 & 4 & 5 & 6 & 7 & 8 & 9 & 10 & 11\end{array}$

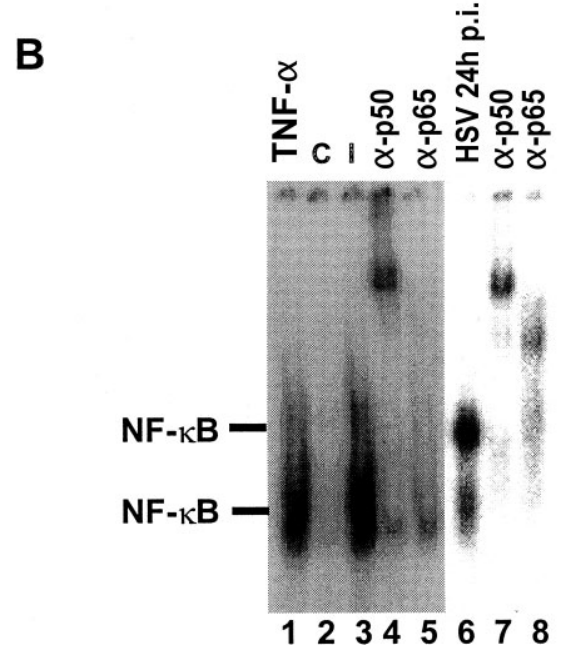

Figure 5 Effect of HSV-1 infection on NF- $\mathrm{BB}$ DNA-binding. (A) HGF cells were infected with HSV-1 (3 pfu/cell) for $1 \mathrm{~h}$ at $37^{\circ} \mathrm{C}$. At different times (15, 18 and 24 h) p.i. nuclear extracts from HSV-1 (HSV) or mock infected (Mock) cultures were prepared and assayed for NF- $\kappa \mathrm{B}$ response element binding activity by electromobility shift assay (EMSA) using the ICAM-1 promoter. Supershifts were performed by including monoclonal antibodies recognising either p65 or p50 as indicated in the Figure. Specificity was verified by competition with the ICAM-1 consensus oligonucleotide mutated at one base (I) as well as by competition with the unlabelled ICAM-1 consensus probe (C). (B) A control experiment was performed using HGF cells treated with tumour necrosis factor (TNF)- $\alpha$ or HSV- 1 to verify the identity of the proteins bound to the labelled oligo. Supershifts were performed by including monoclonal antibodies recognising either p65 or p50 as indicated in the Figure. Specificity was verified by competition with the ICAM-1 consensus oligonucleotide mutated at one base (I) as well as by competition with the unlabelled ICAM-1 consensus probe (C).

migrating band observed in the nuclear extracts of HSV-1 infected cells (Fig. 5B, lane 6) corresponded to the NF- $\mathrm{KB}$ binding activity in TNF- $\alpha$ treated cells (Fig. 5B, lane 1), rather than to the smaller complex comprising the slower 
migrating band. This may indicate that the slower migrating complex could contain additional proteins recruited in response to the HSV-1 infection along with p65 and p50. This notion is further strengthened by the observed increase of the larger complex with time. The recruited proteins may be of viral or cellular origin - ongoing studies will hopefully reveal their identity.

As neither NF- $\mathrm{\kappa B}$ expression nor nuclear translocation was affected, although viral yield differed in the two different dex treatments, we were interested to analyse the binding of the ICAM-1, NF- $\kappa$ B element in an EMSA of dex treated cells. Dex treatment has previously been reported not to affect DNA-binding of TNF- $\alpha$ activated NF- $\kappa B$ (Liden et al. 2000). In line with this, DNAbinding of NF- $\mathrm{KB}$ in HSV-1-infected HGF cells was not affected by dex. HSV-1 infection induced DNA-binding of NF-KB in both dex co-treated (Fig. 6A lanes 4-6) and pre-treated (Fig. 6B lanes 4-6) cultures in a fashion similar to that in non-treated cells. The same change in abundance of the two distinct bands over time as non-treated cells was noted. This result, in combination with the protein expression data, indicates that glucocorticoid treatment does not affect the virus-induced nuclear translocation of NF- $\mathrm{KB}$, nor the ability of p65 and p50 to bind to DNA.

We suggest that the increase in HSV-1 viral yield caused by dex pre-treatment may be due to a limited availability of GR at the time of HSV-1 infection, meaning that GR could not counteract NF- $\mathrm{KB}$ activity. This effect of GR would be expected to occur downstream of the $\mathrm{p} 65$ protein expression, nuclear translocation or DNA-binding ability, as all these features are unchanged from the non-treated cases. This is in line with other reports concerning glucocorticoid effects on NF- $\mathrm{KB}$ signalling in vivo and in vitro, induced by TNF- $\alpha$, showing that GR does not disrupt DNA binding by NF-KB (Nissen \& Yamamoto 2000).

Up-regulation of the viral yield in dex pre-treated cultures is abolished by addition of the antiviral agent $A C V$

One of the reasons to study glucocorticoid effects on HSV-1 infection is the suggestion that glucocorticoids could be used in clinic to treat herpes simplex-related blisters and inflammation. Therefore we investigated whether an antiviral substance, such as ACV, could still exert its effect of inhibiting viral production when glucocorticoids were present. The HGF cells were pre-treated with either dex or dex in combination with ACV $24 \mathrm{~h}$ prior to infection. We used a low MOI $\left(10^{-3} \mathrm{pfu} / \mathrm{cell}\right)$ and measured the viral yield $24 \mathrm{~h}$ after infection in a Vero cell viral plaque assay. The low MOI was used to mimic the in vivo situation and we chose this time point as we assumed that it would correspond to the viral production after one cycle of viral replication in a primary cell. We
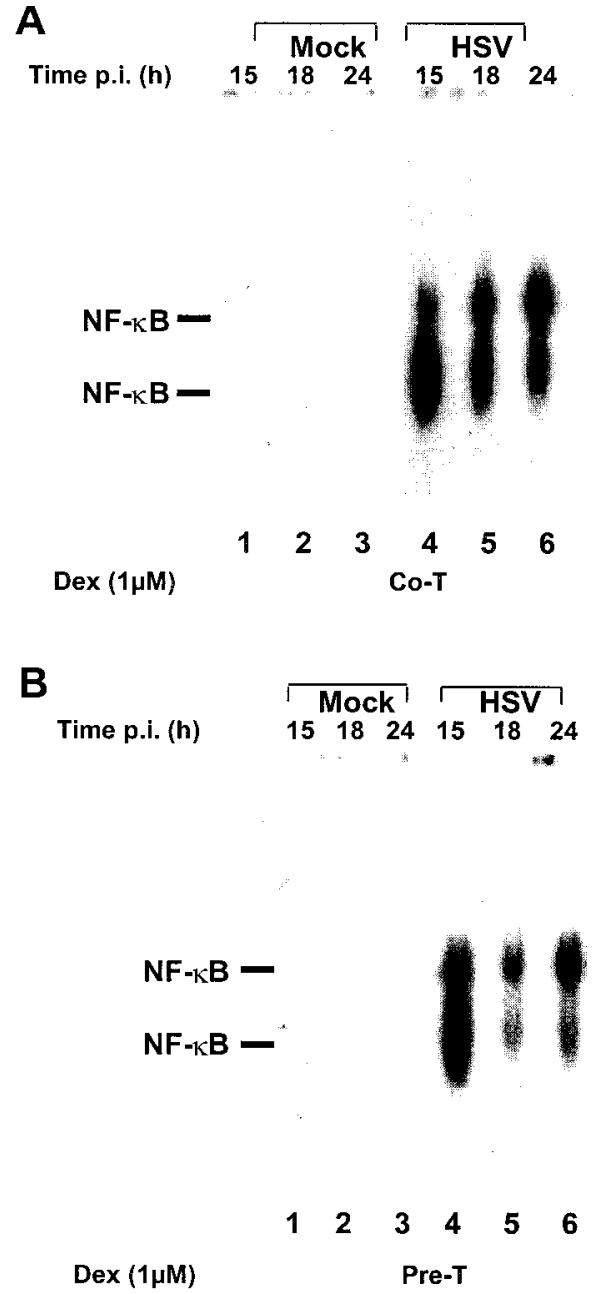

Figure 6 Effects of dex on the DNA-binding of NF- $\kappa B$ in HSV-1 infected cells. HGF cells were either (A) dex co-treated (Co-T) at the time of infection or, (B) pre-treated (Pre-T) $24 \mathrm{~h}$ prior to infection with HSV-1 ( $3 \mathrm{pfu} / \mathrm{cell}$ ) for $1 \mathrm{~h}$ at $37^{\circ} \mathrm{C}$. At different times (15, 18 and 24 h) p.i. nuclear extracts from HSV-1 (HSV) or mock infected (Mock) cultures were prepared and assayed for NF- $\kappa \mathrm{B}$ binding activity by EMSA.

found that ACV in combination with dex could inhibit viral growth to an extent similar to addition of ACV (Fig. 7).

\section{Discussion}

Herpes simplex virus type 1 infection results in a broad spectrum of symptoms from minor to severe, and very painful, lesions. The majority of the adult population is sero-positive and many infected patients suffer from frequent reactivations, causing discomfort and pain to the individual. The symptoms of the reactivated viral infection are, in part, due to the viral cytopathic effect but mainly to 


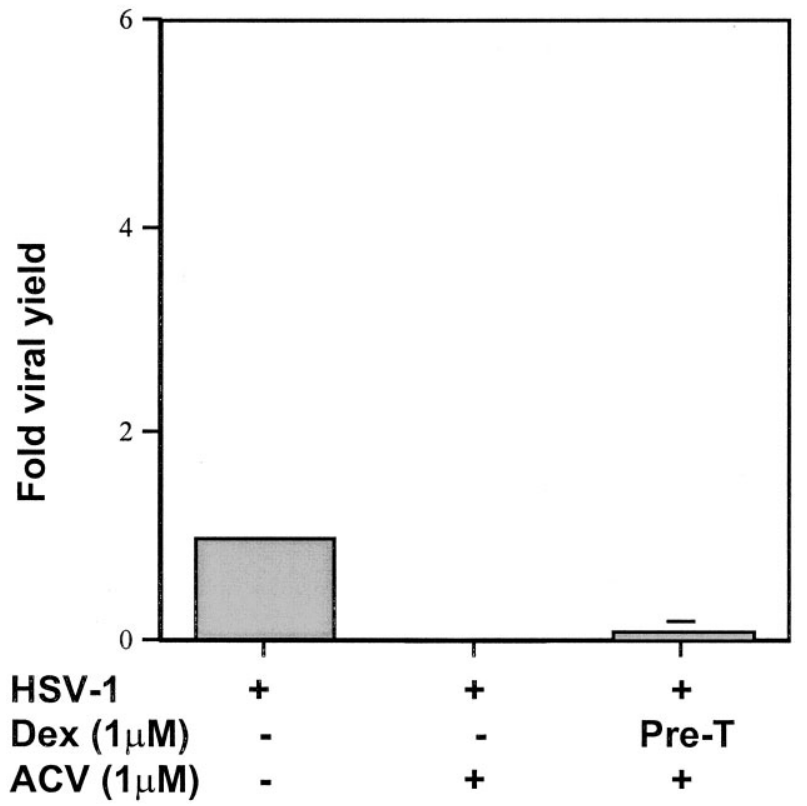

Figure 7 Addition of acyclovir (ACV) inhibits the increased viral yield in HGF cells pre-treated with dex. HGF cells were either untreated or pre-treated with ACV alone or a combination of ACV and dex (Pre-T) $24 \mathrm{~h}$ prior to infection with HSV $-1\left(10^{-3} \mathrm{pfu} / \mathrm{cell}\right)$ for $1 \mathrm{~h}$ at $37^{\circ} \mathrm{C}$. At $24 \mathrm{~h}$ p.i. viral supernatants were removed and diluted to be assayed for pfu content by plaque assay. The results are obtained from six individual experiments and are presented as means $( \pm$ S.D.) fold viral yield compared with untreated control cells.

the immune and inflammatory responses. In most infected individuals the immune system will rapidly counteract viral replication. However, the rapid and persistent immune response causes inflammation with pain and discomfort even after the virus is cleared. Current treatment consists of antiviral agents that are efficient in terminating viral replication but have no effect on the inflammatory response caused by the infection.

Glucocorticoids are widely used to treat inflammatory diseases and could possibly be used to treat inflammatory reactions in HSV-1 recurrences. However, this approach is controversial as some previous in vitro studies report up-regulation of viral yield, while others report the opposite effect on viral yield depending on the cell system and method used. In addition to discussions considering cell systems, methods and strains of virus used, the fact that glucocorticoids also act as immunosuppressants must be taken into consideration. In the intact organism the suppressed immune response might lead to reduced viral clearance causing an increased viral yield. Our first aim was to study how glucocorticoid treatment affected HSV-1 viral yield and also to elucidate some of the molecular consequences of HSV-1 infection on glucocorticoid signalling itself in a non-transformed cell line. Dex treatment of a primary HGF cell culture infected with HSV-1 led to increased virus production in cells pretreated with dex for $24 \mathrm{~h}$ before the infection, but not in cells where dex was added at the time of infection. We used dex at a concentration of $1 \mu \mathrm{M}$; high enough to give rise to a significant glucocorticoid-mediated response, but not to inhibit cellular proliferation or cause toxicity in HGF cells (data not shown).

We went on to study the effect of HSV-1 infection on GR itself and found that HSV-1 infection led to up-regulation and nuclear translocation of GR in HGF cells. In another - GR-deficient - cell line, HEK 293GR, that was transiently transfected with a GR reporter gene, HSV-1 infection led to up-regulated reporter gene activity, without any addition of glucocorticoid. This effect has, to our knowledge, not previously been reported and may indicate that GR regulation is part of the cellular response against viral infections.

Viruses are intracellular microorganisms that take advantage of the host cell machinery to replicate. They have evolved a variety of strategies to target cellular signalling mechanisms to promote their own replication. It has previously been shown that HSV-1 activates several kinases including the c-Jun N-terminal kinase/stressactivated protein kinase (McLean \& Bachenheimer 1999, Zachos et al. 1999) and the p38 MAP kinase and transcription factors such as AP-1 (Zachos et al. 1999) and NF-KB (Rong et al. 1992, Amici et al. 2001). Activation of these signalling pathways has been suggested to be important for viral replication. We demonstrated in our study that HSV-1 infection led to increased levels and nuclear translocation of NF- $\kappa \mathrm{B}$ in primary HGFs. As we discovered an increased viral yield in cells pre- but not cotreated with dex, a well known inhibitor of NF- $\mathrm{KB}$ signalling, we were interested to see whether the NF- $\kappa B$ levels and localisation were regulated differently in cultures pre- and cotreated with dex. We found that dex treatment of HSV-1 infected cells caused up-regulation and nuclear translocation of NF- $\mathrm{KB}$, to a similar extent as in untreated cells, regardless of when the dex was added.

We had seen the effects of HSV-1 on GR levels and signalling and it is known that activated GR usually counteracts NF- $\mathrm{kB}$ signalling, so we also examined whether GR expression was differently regulated by preor co-treatment with dex. As an added level of complexity in this system, the auto-regulation of GR by glucocorticoids should be taken into consideration. Glucocorticoids generally down-regulate GR expression in most cell types and a low level of GR usually results in limited glucocorticoid responsiveness. Furthermore the auto-regulation of GR is time dependent; after $24 \mathrm{~h}$ of glucocorticoid treatment, GR expression was almost undetectable. In HGF cells, dex pre-treatment led to a low GR level at the time of infection. This could be postulated to lead to a diminished ability of GR to counteract NF- $\mathrm{KB}$. Dex co-treated cells, on the other hand, had unaffected levels of GR at the time of infection and the subsequent 
infection-induced rise in GR seemed to keep GR levels high throughout the period studied. In cotreated cells, GR would therefore still be expected to counteract the strong $\mathrm{NF}-\kappa \mathrm{B}$ response in the same fashion as in untreated cells.

We also decided to study the DNA-binding of NF- $\mathrm{KB}$ in this system. We found that the increase of nuclear $\mathrm{NF}-\kappa \mathrm{B}$ in all cases, regardless of when dex was added, led to increased DNA-binding in an EMSA analysis using an NF- $\kappa B$ element from the ICAM-8 promoter. This was similar to that occuring in untreated cells. Whether increased nuclear translocation of NF- $\mathrm{\kappa B}$ is in general followed by increased target gene transcription is unclear. Patel and co-workers (1998) have reported transrepression while Amici and co-workers (2001) have suggested that HSV-1 infection leads to transactivation of an NF- $\mathrm{KB}$ target gene. The effect of NF- $\mathrm{KB}$ on viral replication in a cell system where degradation of IKB is inhibited has been studied, either by using cells expressing a constitutive IКB that is not degraded in response to NF- $\mathrm{KB}$ inducing agents, or by treatment with IKB kinase (IKK) inhibitors. As the viral yield is significantly decreased in these studies it has been concluded that nuclear translocation of NF- $\mathrm{KB}$ is necessary for efficient viral replication. However, it is not possible to conclude from these studies whether actual $\mathrm{NF}-\mathrm{KB}$ transactivation activity is required. In this context it should be noted that it has previously been shown that TNF- $\alpha$-induced NF- $\kappa B$ nuclear translocation and DNAbinding is not affected by dex, but dex still inhibits the transactivation of NF- $\mathrm{KB}$ target genes (Liden et al. 2000).

It is possible to explain our findings if we speculate that the DNA-binding of NF- $\mathrm{KB}$, also when induced by viral infection, leads to transactivation of NF- $\kappa \mathrm{B}$ regulated genes and that this transactivation is required for viral replication. This NF- $\mathrm{KB}$ transactivation could be counteracted by glucocorticoids acting via GR when levels of the receptor are normal, as they are when the cells are non- or cotreated with dex, but not when GR levels are downregulated by dex pre-treatment. This would not be reflected in differences in NF- $\mathrm{KB}$ EMSA patterns in these various cases. Further attempts to study NF- $\mathrm{BB}$ transactivation induced by HSV-1 infection in the presence of dex are in progress in our laboratory.

In addition to increased nuclear translocation of NF- $\mathrm{KB}$ in response to HSV-1 infection, we also noted that the multiprotein complex binding to the NF- $\mathrm{KB}$ recognition sequence changed in composition over time. The binding complexes present in nuclear extracts from HSV-1 infected HGF cells consisted of two sub-populations with different migration abilities in the EMSA. However, both complexes were supershifted by the two anti-NF- $\kappa B$ antibodies used for specificity control, anti-p50 and anti-p65. One explanation may be that the larger complex consists of additional proteins, either of viral of host cellular origin, induced by the infection. Further studies are in progress to determine the nature of these complexes.
The findings in this report also point to a possible explanation for the reactivation of HSV infections by stress. Stress causes an increase of endogenous glucocorticoids that initially activates and then eventually auto-downregulates GR expression (Song et al. 1991, Herman et al. 1995). In the intact organism the multifaceted response to infections involve glucocorticoid release and GR activation, probably to counteract and terminate the defence mechanisms to the infection (reviewed in Mercurio \& Manning 1999). Decreased levels of GR could lead to reduced control over NF- $\kappa \mathrm{B}$ action. We suggest that the low levels of GR after a stressful event may be one explanation for HSV-1 reactivation.

The use of glucocorticoids as an adjuvant therapy for infectious diseases is controversial. In the in vivo situation, as noted above, one has to take into consideration that glucocorticoid treatment acts to suppress the immune system, which could lead to increased viral titres. Although glucocorticoids are considered by many to act permissively for viral infections there are also reports indicating beneficial effects in glucocorticoid treatment of some infections (Wilhelmus et al. 1994, O'Brien et al. 1996) and acute respiratory distress syndrome (Meduri et al. 2002). Contrary to the effect of glucocorticoids on HSV-1 replication demonstrated in this report, there exists some experimental evidence that administration of corticosteroids with or without antibiotics may be therapeutic in bacterial infections such as Mycoplasma pulmonis under certain conditions (Bowden et al. 1994). We noted that the GR protein was suppressed to almost undetectable levels after $24 \mathrm{~h}$ dex treatment and that this protein was normally upregulated as a consequence of HSV-1 infection. This, and the fact that GR normally counteracts NF- $\kappa B$, led us to suggest that the lack of sufficient GR may cause increased viral replication. Other host cell factors not identified in this study may, of course, also be of importance.

We tested the concept of anti-viral therapy combined with glucocorticoid adjunct therapy in this system. As we had established the conditions under which viral yield could be expected to be up-regulated, it was possible to study whether the anti-viral drug maintained its efficacy in the presence of dex. By choosing a sub-optimal dose of ACV $(1 \mu \mathrm{M})$ the system was rendered sensitive to changes in viral yield. Even this low dose of ACV was as efficient when combined with dex as it was alone. $1 \mu \mathrm{M}$ ACV was sufficient to block the viral replication even in the case of a sixfold increase in the viral yield in response to glucocorticoid treatment,

In summary, we suggest that increased insight into the interplay of various pathogens and immunoendocrine host responses such as inflammation and GR signalling may be relevant for the development of model systems to test new treatment strategies for viral diseases. 


\section{Acknowledgements}

We thank M Rönnholm for her excellent technical assistance. This work was supported by the Foundation for Knowledge and Competence, Stockholm, Medivir AB, Stockholm, Åke Wibergs Foundation, Research Foundation of the Karolinska Institutet and Swedish Medical Research Council grants 12557 and KI 13X-281.

\section{References}

Adcock IM 2000 Molecular mechanisms of glucocorticosteroid actions. Pulmonary Pharmacology Therapy 13 115-126.

Amici C, Belardo G, Rossi A \& Santoro MG 2001 Activation of ikappa $\mathrm{b}$ kinase by herpes simplex virus type 1 . A novel target for anti-herpetic therapy. Journal of Biological Chemistry 276 28759-28766.

Baldwin AS Jr 1996 The NF-kappa B and I kappa B proteins: new discoveries and insights. Annual Review in Immunology 14 649683.

Barnes PJ \& Adcock I 1993 Anti-inflammatory actions of steroids: molecular mechanisms. Trends in Pharmacological Sciences 14 436441.

Barnes PJ \& Karin M 1997 Nuclear factor-kappaB: a pivotal transcription factor in chronic inflammatory diseases. New England Journal of Medicine 336 1066-1071.

Bowden JJ, Schoeb TR, Lindsey JR \& McDonald DM 1994 Dexamethasone and oxytetracycline reverse the potentiation of neurogenic inflammation in airways of rats with Mycoplasma pulmonis infection. American Journal of Respiratory Critical Care in Medicine 150 1391-1401.

Caldenhoven E, Liden J, Wissink S, Van de Stolpe A, Raaijmakers J, Koenderman L, Okret S, Gustafsson JÅ \& Van der Saag PT 1995

Negative cross-talk between RelA and the glucocorticoid receptor: a possible mechanism for the antiinflammatory action of glucocorticoids. Molecular Endocrinology 9 401-412.

Dong Y, Poellinger L, Gustafsson JÅ \& Okret S 1988 Regulation of glucocorticoid receptor expression: evidence for transcriptional and posttranslational mechanisms. Molecular Endocrinology 2 $1256-1264$

Dreyer LL, Sydiskis RJ \& Bashirelahi N 1989 Effect of dexamethasone on herpes simplex virus replication in mouse neuroblastoma cells (NB41A3): receptor characteristics. Journal of Clinical Laboratory Analysis 3 236-243.

Erdeljan P, MacDonald JF \& Matthews SG 2001 Glucocorticoids and serotonin alter glucocorticoid receptor (GR) but not mineralocorticoid receptor (MR) mRNA levels in fetal mouse hippocampal neurons, in vitro. Brain Research 896 130-136.

Ghosh D 1992 Glucocorticoid receptor-binding site in the human immunodeficiency virus long terminal repeat. Journal of Virology 66 586-590.

Hardwicke MA \& Schaffer PA 1995 Cloning and characterisation of herpes simplex virus type 1 oriL: comparison of replication and protein-DNA complex formation by oriL and oriS. Journal of Virology 69 1377-1388.

Hardwicke MA \& Schaffer PA 1997 Differential effects of nerve growth factor and dexamethasone on herpes simplex virus type 1 oriL- and oriS-dependent DNA replication in PC12 cells. Journal of Virology $713580-3587$.

Harrell AJ \& Sydiskis RH 1982 The effect of dexamethasone on the replication of herpes simplex virus in human gingival fibroblast cultures. Journal of Baltimore College in Dental Surgery 35 9-13.

Herman JP, Adams D \& Prewitt C 1995 Regulatory changes in neuroendocrine stress-integrative circuitry produced by a variable stress paradigm. Neuroendocrinology 61 180-190.
Holloway AC, Whittle WL \& Challis JR 2001 Effects of cortisol and estradiol on pituitary expression of proopiomelanocortin, prohormone convertase-1, prohormone convertase-2, and glucocorticoid receptor mRNA in fetal sheep. Endocrine 14 343-348.

Kino T, Gragerov A, Kopp JB, Stauber RH, Pavlakis GN \& Chrousos GP 1999 The HIV-1 virion-associated protein vpr is a coactivator of the human glucocorticoid receptor. Journal of Experimental Medicine 189 51-62.

Kino T, Kopp JB \& Chrousos GP 2000 Glucocorticoids suppress human immunodeficiency virus type-1 long terminal repeat activity in a cell type-specific, glucocorticoid receptor-mediated fashion: direct protective effects at variance with clinical phenomenology. Journal of Steroid Biochemistry and Molecular Biology 75 283-290.

Liden J, Rafter I, Truss M, Gustafsson JA \& Okret S 2000 Glucocorticoid effects on NF-kappaB binding in the transcription of the ICAM-1 gene. Biochemical and Biophysical Research Communications 273 1008-1014.

McLean TI \& Bachenheimer SL 1999 Activation of cJUN N-terminal kinase by herpes simplex virus type 1 enhances viral replication. Journal of Virology 73 8415-8426.

Markham PD, Salahuddin SZ, Popovic M, Patel A, Veren K, Fladager A, Orndorff S \& Gallo RC 1985 Advances in the isolation of HTLV-III from patients with AIDS and AIDS-related complex and from donors at risk. Cancer Research 45 4588s-4591s.

Markham PD, Salahuddin SZ, Veren K, Orndorff S \& Gallo RC 1986 Hydrocortisone and some other hormones enhance the expression of HTLV-III. International Journal of Cancer 37 67-72.

Meduri GU, Tolley EA, Chrousos GP \& Stentz F 2002 Prolonged methylprednisolone treatment suppresses systemic inflammation in patients with unresolving acute respiratory distress syndrome: evidence for inadequate endogenous glucocorticoid secretion and inflammation-induced immune cell resistance to glucocorticoids. American Journal of Respiratory Critical Care Medicine 165 983-991.

Mercurio F \& Manning AM 1999 NF-kappaB as a primary regulator of the stress response. Oncogene 18 6163-6171.

Newton R 2000 Molecular mechanisms of glucocorticoid action: what is important? Thorax $\mathbf{5 5}$ 603-613.

Nissen RM \& Yamamoto KR 2000 The glucocorticoid receptor inhibits NFkappaB by interfering with serine-2 phosphorylation of the RNA polymerase II carboxy-terminal domain. Genes Deviation 14 2314-2329.

Notter MF \& Docherty JJ 1978 Steroid hormone alteration of herpes simplex virus type 1 replication. Journal of Medicinal Virology 2 247-252.

O'Brien WJ, Segundo AP, Guy J, Dorn EM \& Taylor JL 1996 Herpetic stromal disease: response to acyclovir/steroid therapy. Acta Ophthalmology Scandinavia 74 265-270.

Patel A, Hanson J, McLean TI, Olgiate J, Hilton M, Miller WE \& Bachenheimer SL 1998 Herpes simplex type 1 induction of persistent NF-kappa B nuclear translocation increases the efficiency of virus replication. Virology 247 212-222.

Refaeli Y, Levy DN \& Weiner DB 1995 The glucocorticoid receptor type II complex is a target of the HIV-1 vpr gene product. PNAS $923621-3625$.

Rong BL, Libermann TA, Kogawa K, Ghosh S, Cao LX, Pavan-Langston D \& Dunkel EC 1992 HSV-1-inducible proteins bind to NF-kappa B-like sites in the HSV-1 genome. Virology 189 750-756.

Schule R, Muller M, Kaltschmidt C \& Renkawitz R 1988 Many transcription factors interact synergistically with steroid receptors. Science 242 1418-1420.

Song LN, Yang YL \& Xu RB 1991 Stress-induced regulation of glucocorticoid receptor gene expression in the rat. Receptor $\mathbf{1}$ 207-216

Tomita M, Chrousos GP, Brandon DD, Ben-Or S, Foster CM, De Vougn L, Taylor S, Loriaux DL \& Lipsett MB 1985 Glucocorticoid 
receptors in Epstein-Barr virus-transformed human lymphocytes. Hormone Metabolism Research 17 674-678.

Wilhelmus KR, Gee L, Hauck WW, Kurinij N, Dawson CR, Jones DB, Barron BA, Kaufman HE, Sugar J, Hyndiuk RA et al. 1994 Herpetic Eye Disease Study. A controlled trial of topical corticosteroids for herpes simplex stromal keratitis. Ophthalmology 101 1883-1896.
Zachos G, Clements B \& Conner J 1999 Herpes simplex virus type 1 infection stimulates $\mathrm{p} 38 / \mathrm{c}$-Jun N-terminal mitogen-activated protein kinase pathways and activates transcription factor AP-1. Journal of Biological Chemistry 274 5097-5103.

Received 30 April 2002

Accepted 7 June 2002 